\title{
Sensitivity of Entomopathogenic Fungi and Bacteria to Plants Secondary Metabolites, for an Alternative Control of Rhipicephalus (Boophilus) microplus in Cattle
}

OPEN ACCESS

Edited by:

Filippo Maggi,

University of Camerino, Italy

Reviewed by:

Gokhan Zengin,

Selçuk University, Turkey

Javad Sharifi-Rad,

Shahid Beheshti University of Medical

Sciences, Iran

${ }^{*}$ Correspondence:

Simona Nardon

simona.nardoni@unipi.it

Specialty section:

This article was submitted to

Ethnopharmacology,

a section of the journal

Frontiers in Pharmacology

Received: 20 June 2018

Accepted: 30 July 2018

Published: 14 August 2018

Citation:

Nardoni S, Ebani W, D'Ascenzi C,

Pistelli L and Mancianti F (2018)

Sensitivity of Entomopathogenic Fungi

and Bacteria to Plants Secondary

Metabolites, for an Alternative Control

of Rhipicephalus (Boophilus)

microplus in Cattle.

Front. Pharmacol. 9:937.

doi: 10.3389/fphar.2018.00937

\author{
Simona Nardoni1,2*, Valentina V. Ebani ${ }^{1,2}$, Carlo D'Ascenzi ${ }^{1,2}$, Luisa Pistelli2,3 and \\ Francesca Mancianti ${ }^{1,2}$
}

${ }^{1}$ Dipartimento di Scienze Veterinarie, Università di Pisa, Pisa, Italy, ${ }^{2}$ Centro Interdipartimentale di Ricerca "Nutraceutica e

Alimentazione per la Salute", Università di Pisa, Pisa, Italy, ${ }^{3}$ Dipartimento di Farmacia, Università di Pisa, Pisa, Italy

Boophilus (Rhipicephalus) microplus is a one host hard tick widespread in warm climates worldwide, responsible for great economic losses. To avoid resistance in ticks population, induced by the repeated administration of conventional acaricides and/or the presence of residues in the environment in meat and in milk, an alternative approach can be achieved using entomopathogenic microorganisms such as fungi and bacteria, or essential oils (EOs). The aim of the present study was to evaluate the in vitro sensitivity of Beauveria bassiana, Metarhizium anisopliae, Scopulariopsis sp, Bacillus thuringiensis and Proteus mirabilis to Eucalyptus globulus, Lavandula hybrida, Pelargonium graveolens EOs and to their main constituents such as lynalool, linalylacetate, geraniol, citronellol and 1,8 cineole. EOs has been chemically characterized by GC-MS. Fungal isolates were tested by a microdilution assay to achieve minimal inhibitory concentration (MIC) of both EOs and main components. The sensitivity of bacteria was evaluated by an agar disk diffusion. The results obtained show the feasibility of an integrate approach for an eco-friendly control of $R$. microplus by use of both entomopathogenic fungi and P. graveolens EO. L. hybrida could be an interesting alternative when $B$. bassiana is not employed. Conversely, a combined use of $B$. thuringiensis and EOs would not be advisable in the integrate control of ticks.

Keywords: ticks, Metarhizium anisopliae, Beauveria bassiana, Bacillus thuringiensis, Proteus mirabilis, essential oils, acaricide activity, repellent activity

\section{INTRODUCTION}

Boophilus microplus, recently recognized as Rhipicephalus (Boophilus) microplus, is a one host hard tick, present in warm climates worldwide. This Ixodidae species is considered the most damaging cattle ectoparasite, acting as vector of Babesia bigemina, Babesia bovis and Anaplasma marginale (Banumathi et al., 2017). Furthermore R. microplus can cause anemia, weight loss, and reduction of productive performances (Jonsson, 2006), being together with costs of specific drugs, responsible for great economic losses (Rachinsky et al., 2008).

The control of this agent represents a main concern and relies on both chemical and nonchemical treatments. Conventional control is based on chemical acaricides (Cruz et al., 2015), however repeated administrations of these compounds may induce resistance in tick population 
(Klafke et al., 2017). Moreover these drugs contaminate the environment as well as meat and, in dairy cows, milk. An alternative approach can be achieved using entomopathogenic microorganisms such as fungi and bacteria, or using active compounds from different botanical species.

Some entomopathogenic fungi, such as Beauveria bassiana and Metarhizium anisopliae, have been evaluated for ticks' control (Kaaya et al., 2011; Ren et al., 2016; González et al., 2016; Aw and Hue, 2017). Conversely, Scopulariopsis brevicaulis, an environmental deuteromycetes, is considered as a commensal of ticks (Yoder et al., 2005) and would protect some Ixodida species from M. anisopliae proliferation (Yoder et al., 2008).

Entomopathogenic bacteria and their derived products are also considered useful for a biological control of arthropods. Some bacterial species have been demonstrated to be pathogenic for ticks. Among them Bacillus thuringiensis is the most studied entomopathogen, active versus ticks (Fernández-Ruvalcaba et al., 2010) and largely employed in commercial insecticide formulations. The pathogenic action of this bacterium normally occurs after ingestion of spores and crystalline inclusions containing insecticidal $\delta$-endotoxins that specifically interact with receptors in the insect midgut epithelial cells (Bravo et al., 2007).

Tick pathogenic property of Proteus mirabilis has been reported (Brown et al., 1970), also. P. mirabilis is an opportunistic bacterium spread in the environment. In fact, it is normally present in the intestinal tract of several animal species, including cattle (Drzewiecka, 2016).

Essential oils (EOs) are secondary plants metabolites, which may show antimicrobial properties (Salehi et al., 2018; SharifiRad et al., 2018a,b,c; Prakash Mishra et al., 2018). Some of them are proven to exert an acaricidal activity (Pirali-Kheirabadi and Teixeira da Silva, 2010, 2011; de Souza Chagas et al., 2012; Banumathi et al., 2017; Rosado-Aguilar et al., 2017). Moreover several EOs posses antifungal and antibacterial activities. So, in view of a combined use of both entomopathogenic organisms and EOs in an eco-friendly way of ticks' control, the aim of the present study was to evaluate the in vitro sensitivity of B. bassiana, $M$. anisopliae, S. brevicaulis, $B$. thuringiensis and $P$. mirabilis isolates to Eucalyptus globulus, Lavandula hybrida and Pelargonium graveolens EOs and to their main constituents. These EOs, in fact would exert both acaricidal and/or repellent activities, respectively, against several tick species. The results obtained would allow the determination of compound concentrations able to exert acaricide and/or repellent actions, without damaging entomopathogenic organisms.

\section{MATERIALS AND METHODS}

\section{Essential Oils and Their Major Components}

The study was performed employing the following EOs: lavender (L. hybrida), eucalyptus (E. globulus) and geranium (P. graveolens) and some of their major components (lynalool, linalyl-acetate, geraniol, citronellol and 1,8 cineole). All EOs were obtained from the producer $\left(\mathrm{FLORA}^{\circledR}\right.$, Pisa, Italy), while single components were purchased from Sigma (Sigma Aldrich, Germany). They were maintained at $4^{\circ} \mathrm{C}$ in dark glass vials and were microbiologically analyzed for quality control before use.

\section{Gas Chromatography - Mass Spectrometry Analysis}

Essential oils were chemically characterized by Gas Chromatography - Mass Spectrometry Analysis (GC-MS). The analysis was performed as previously described (Ebani et al., 2016). Briefly, The GC analysis were accomplished with an HP-5890 Series II instrument equipped with a HP-Wax and HP-5 capillary columns (both $30 \mathrm{~m} \times 0.25 \mathrm{~mm}, 0.25 \mu \mathrm{m}$ film thickness), working with the following temperature program: $60^{\circ} \mathrm{C}$ for $10 \mathrm{~min}$, rising at $5^{\circ} \mathrm{C} / \mathrm{min}$ to $220^{\circ} \mathrm{C}$. The injector and detector temperatures were maintained at $250^{\circ} \mathrm{C}$; carrier gas, nitrogen ( $2 \mathrm{~mL} / \mathrm{min})$; detector, dual FID; split ratio 1:30. The volume injected was $0.5 \mu \mathrm{L}$. The relative proportions of the oil constituents were percentages obtained by FID peak-area normalization without the use of a response factor. GC-MS analyses were performed with a Varian CP-3800 gas chromatograph equipped with a DB-5 capillary column $(30 \mathrm{~m} \times 0.25$; coating thickness, $0.25 \mu \mathrm{m})$ and a Varian Saturn 2000 ion trap mass detector. Analytical conditions were as follows: injector and transfer line temperatures, 220 and $240^{\circ} \mathrm{C}$ at $3^{\circ} \mathrm{C} / \mathrm{min}$, respectively; oven temperature, programmed from 60 to $240^{\circ} \mathrm{C}$ at $3^{\circ} \mathrm{C} / \mathrm{min}$; carrier gas, helium at $1 \mathrm{~mL} / \mathrm{min}$; injection, $0.2 \mu \mathrm{L}$ (10\% hexane solution); split ratio, 1:30. Identification of the constituents was based on comparison of the retention times with those of authentic samples, comparing their linear retention indices relative to the series of $\mathrm{n}$-hydrocarbons, and on computer matching against commercial and home-made library mass spectra built up from pure substances and components of known oils and MS literature data.

\section{Acaricidal/Repellent Activities of Compounds}

Acaricidal activity of selected EOs and both acaricidal and repellent effect of their main components were assayed on R. microplus adult engorged females and larvae, respectively, as described by Pirali-Kheirabadi and Teixeira da Silva (2010) and by Wanzala et al. (2014), with slight modification. In detail, serial EOs and components concentrations $(0.5,1,1.5,2.0,3.0,4.0$ and $5 \mathrm{v} / \mathrm{v}$ percentages, using $60 \%$ ethanol as solvent) were achieved and acaricidal activity was evaluated dipping 5 engorged female ticks. A control group consisted of 5 R. microplus adult engorged females, dipped in $60 \%$ ethanol without EOs. All determinations were performed in triplicate. Ticks were checked for viability at 6,18 and $24 \mathrm{~h}$ post dipping. Repellent effect was evaluated by tick climbing bioassay (Wanzala et al., 2004), carried out in 5 replicates, using serial components concentrations $(0.1,0.5,1$, $2,4,5,7,10 \mathrm{v} / \mathrm{v}$ percentages) on larvae. The repellency of each concentrations was empirically evaluated counting the number of ticks that climbed the treated and control glass tube respectively.

\section{Antifungal Activity Fungal Strains}

A strain each of 2 entomopathogenic fungi ( $M$. anisopliae CBS 115995 and B. bassiana CBS 100544) were provided 
TABLE 1 | Chemical composition of tested EOs.

\begin{tabular}{|c|c|c|c|c|c|}
\hline \multirow[t]{3}{*}{ Component } & \multirow{3}{*}{$\begin{array}{l}\text { Class of } \\
\text { constituents }\end{array}$} & \multirow{3}{*}{ LRI $^{\text {a) }}$} & \multicolumn{3}{|c|}{ EO tested } \\
\hline & & & L. $h$ & P. $g$ & E. $g$ \\
\hline & & & \multicolumn{3}{|c|}{ Relative abundance (\%) } \\
\hline$\alpha$-Thujene & $\mathrm{MH}$ & 930 & & & \\
\hline$\alpha$-Pinene & $\mathrm{MH}$ & 939 & & & 2.0 \\
\hline Sabinene & $\mathrm{MH}$ & 975 & 0.1 & & \\
\hline$\beta$-Pinene & $\mathrm{MH}$ & 979 & 0.4 & & \\
\hline$\alpha$-Phellandrene & $\mathrm{MH}$ & 1003 & & & \\
\hline$\alpha$-Terpinene & $\mathrm{MH}$ & 1017 & & & \\
\hline p-Cymene & $\mathrm{MH}$ & 1025 & & & 67.7 \\
\hline o-Cymene & $\mathrm{MH}$ & 1026 & & & \\
\hline$\gamma$-Terpinene & $\mathrm{MH}$ & 1060 & 0.1 & & \\
\hline Terpinolene & $\mathrm{MH}$ & 1089 & 0.5 & & \\
\hline Linalool & $\mathrm{OM}$ & 1097 & 31.5 & 3.9 & \\
\hline Camphor & $\mathrm{OM}$ & 1146 & 7.3 & & \\
\hline Menthone & $\mathrm{OM}$ & 1153 & & 1.1 & \\
\hline Citronellal & $\mathrm{OM}$ & 1153 & & & \\
\hline iso-Menthone & $\mathrm{OM}$ & 1163 & & 3.5 & \\
\hline Menthofuran & $\mathrm{OM}$ & 1164 & & & \\
\hline Menthol & OM & 1172 & & & \\
\hline 4-Terpineol & $\mathrm{OM}$ & 1177 & 4.0 & & \\
\hline$\alpha$-Terpineol & $\mathrm{OM}$ & 1189 & 2.1 & 0.3 & \\
\hline Menthyl acetate & $\mathrm{OM}$ & 1295 & & & \\
\hline Eugenol & $\mathrm{PP}$ & 1359 & & & \\
\hline$\beta$-Caryophyllene & $\mathrm{SH}$ & 1419 & 2.2 & 0.7 & \\
\hline Germacrene D & $\mathrm{SH}$ & 1485 & 0.8 & 0.2 & \\
\hline Eugenyl acetate & PP & 1523 & & & \\
\hline$\delta$-Cadinene & $\mathrm{SH}$ & 1523 & & 0.7 & \\
\hline$\tau$-Cadinol & os & 1640 & 0.2 & & \\
\hline Unknown & & & & 0.7 & \\
\hline Total Identified (\%) & & & 100.0 & 99.3 & 100.0 \\
\hline Class of compounds ${ }^{a)}$ & & & L. $h$ & $P . g$ & E. $g$ \\
\hline Monoterpene hydrocarbons (MH) & & & 6.4 & & 9.1 \\
\hline Oxygenated monoterpenes (OM) & & & 85.0 & 83.4 & 90.5 \\
\hline Sesquiterpene hydrocarbons (SH) & & & 5.4 & 7.8 & 0.3 \\
\hline Oxygenated sesquiterpenes (OS) & & & 1.3 & 6.9 & 0.1 \\
\hline Phenylpropanoides (PP) & & & & 1.2 & \\
\hline Non-terpenes (NT) & & & 1.9 & & \\
\hline
\end{tabular}

a) Linear retention indices on the DB5 column. L.h.: Lavandula hybrida; P.g.: Pelargonium graveolens; E.g.: Eucalyptus globulus. 
TABLE 2 | Biological activities of selected essential oils and components against fungi, bacteria and ticks tested in the study.

\begin{tabular}{|c|c|c|c|c|c|c|c|c|}
\hline & $\begin{array}{c}\text { Lavandula } \\
\text { hybrida }\end{array}$ & $\begin{array}{c}\text { Pelargonium } \\
\text { graveolens }\end{array}$ & $\begin{array}{c}\text { Eucalyptus } \\
\text { globulus }\end{array}$ & Geraniol & 1,8 cineole & Linalool & Linalyl acetate & Citronellol \\
\hline Metarhizium anisopliae & 5 & 5 & 5 & 1 & $>1$ & 2.5 & 5 & 7 \\
\hline Beauveria bassiana & 1 & 5 & 5 & 1 & 0.5 & 2.5 & 5 & 2.5 \\
\hline Scopulariopsis brevicaulis & 2.5 & $>5$ & 2.5 & 1 & $>1$ & $>5$ & $>5$ & 7 \\
\hline Bacillus thuringiensis & 1.25 & 1.25 & 5 & 10 & ne & 10 & ne & 10 \\
\hline Proteus mirabilis & 5 & 5 & 5 & ne & ne & ne & ne & ne \\
\hline Rhipicephalus microplus & 1 & 1.5 & $>5$ & $1 / 1^{*}$ & $0.5^{*}$ & $>10^{*}$ & $>10^{*}$ & $7^{*}$ \\
\hline
\end{tabular}

*repellent activity. Values are expressed as percentage. Only compounds with relative abundance (\%) > 3\% have been included in this table.

by Westerdijk Fungal Biodiversity Institute (Utrecht, The Netherlands) while an isolate of $S$. brevicaulis was obtained from animal fur specimens; all molds were used for in vitro sensitivity assays. All fungi were maintained on Malt Extract Agar (MEA) at room temperature until use.

\section{Microdilution Test}

The antimycotic activity of EOs was checked by a microdilution test carried out as recommended by Clinical and Laboratory Standards Institute M38-A2 for molds (CLSI, 2008), starting from a $5 \%$ dilution. In detail $5,2.5,1.5,1,0.5,0.25$, and $0.1 \%$ dilutions were prepared. Inocula formed by $10^{4} \mathrm{CFU} / \mathrm{ml}$ in RPMI were incubated at $25^{\circ} \mathrm{C}$ evaluated for growth inhibition in 96 - wells plates. The antimycotic activity of all components was evaluated at concentrations of $5,2.5,1,0.5$, and $0.25 \%$. MIC was determined as the lowest concentration of each EO that substantially inhibited fungal growth as detected visually. All assays were performed in triplicate.

\section{Antibacterial Activity \\ Bacterial Strains}

Bacillus thuringiensis ATCC ${ }^{\circledR} 33679^{\mathrm{TM}}$ and Proteus mirabilis ATCC $^{\circledR} 7002^{\text {TM }}$ were provided by Microbiologics (St. Cloud, MN, United States). Both strains were cultured on Tryptic Soy Broth Agar (Oxoid LTD Basingstoke, Hampshire, England) and incubated at $37^{\circ} \mathrm{C}$ before the in vitro sensitivity test.

\section{Minimum Inhibitory Assay}

Antibacterial activity and minimum inhibitory concentration (MIC) of each EO and of selected components against both bacterial strains were tested by the broth microdilution method, on the basis of the protocol reported by Lević et al. (2011) with some modification. The bacterial inoculates were prepared using overnight cultures and suspensions were adjusted to 0.5 McFarland standard turbidity. The assay was carried out in Brain Hearth Infusion Broth (BHIB, Oxoid). The test was performed in a total volume of $200 \mu \mathrm{l} /$ well containing $20 \mu \mathrm{l}$ of each bacterial suspension, $160 \mu \mathrm{l}$ of BHIB and $20 \mu \mathrm{l}$ of each EO/component with final EOs and components concentrations of 10, 5, 2.5, 1.25, and $0.6 \%(\mathrm{v} / \mathrm{v})$. Plates were incubated at $37^{\circ} \mathrm{C}$ for $24 \mathrm{~h}$.

The assay was simultaneously executed for sterility control (tested oil/component and BHIB) and bacterial growth control (tested bacteria and BHIB). The MIC value was defined as the lowest concentration of EO/component at which microorganisms show no visible growth. All tests were performed in triplicate.

\section{RESULTS}

\section{Gas Chromatography - Mass Spectrometry Analysis}

The chemical composition of selected EOs is reported in Table 1. All the EOs showed high percentages of oxygenate monoterpenes, ranging from $83.4 \%$ (P. graveolens) to $90.5 \%$ (E. globulus). $P$. graveolens contained more sesquiterpene hydrocarbons and oxygenate sesquiterpenes, when compared to the other EOs. L. hybrida EO was rich in linalool (31.5\%) and linalyl acetate (26.8\%), P. graveolens contained high amounts of citronellol $(44.5 \%)$ and geraniol $(13.7 \%)$, while the major components of E. globulus were p-cymene (67.7\%) and 1,8 cineole (89.8\%).

\section{Acaricidal/Repellent Activities of Compounds}

The selected EOs showed different degrees of acaricidal activities. EO from lavender appeared as the most active, with a MIC of $1 \%$, followed by geranium $(1.5 \%)$, while a $5 \%$ concentration of eucalyptus EO did not affect ticks viability. Among the selected compounds, geraniol was acaricide at $1 \%$ dilution. The strongest repellent effect was showed by 1,8 cineole $(0.5 \%)$, followed by geraniol (1\%). Linalool failed to show a repellent activity, as well as linalyl-acetate. All replicates within the same tested concentrations of both EOs and components yielded the same value.

\section{Antifungal Activity}

Lavandula hybrida EO showed a MIC of 5\% for M. anisopliae and $1 \%$ for B. bassiana. P. graveolens and E. globulus EOs scored active at $5 \%$ against both entomopathogenic fungi; geraniol was effective at $1 \%$. S. brevicaulis was resistant to more than $5 \%$ EO of $P$. graveolens and $2.5 \%$ of the other EOs. All components used for repellency testing yielded MIC values higher or equal to repellent ones.

\section{Antibacterial Activity}

Pelargonium graveolens and L. hybrida EOs showed a MIC of $1.25 \%$ against $B$. thuringiensis and $5 \%$ versus $P$. mirabilis. E. globulus showed a MIC value of $5 \%$ for both bacterial strains. 
All the selected components were not effective against P. mirabilis. B. thuringiensis resulted sensible to geraniol, citronellol and linalool at 10\%, whereas linalyl-acetate and 1,8cineole resulted uneffective at the same concentration.

Bacterial growth was detected when bacteria had been incubated only with BHIB, whereas it was not observed in the sterility control wells.

More detailed data are provided in Table 2.

\section{DISCUSSION}

Results from the present study represent the first evidence about the acaricidal activity of lavender (L. hybrida), eucalyptus (E. globulus) and geranium (P. graveolens) EOs against $R$. microplus engorged females, and their possible use in synergistic effect with entomopathogenic microorganisms. Findings obtained appeared promising, mainly referred to antifungal results.

The three EOs examined in the present study showed different degrees of bioactivity both versus $R$. microplus and tested molds and bacteria. E. globulus EO was the only compound previously assayed against ticks (Pirali-Kheirabadi and Teixeira da Silva, 2010 ) yielding an acaricide action on $37.5 \%$ of ticks, when used at a $5 \%$ dilution. In the present study, P. graveolens was essayed, instead of $P$. roseum (Pirali-Kheirabadi and Teixeira da Silva, 2010) and showed a good activity at $1.5 \%$, while L. hybrida, instead of Lavandula angustifolia (Pirali-Kheirabadi and Teixeira da Silva, 2011) was active at 1\%. Furthermore, among the main components of selected oils, geraniol showed an acaricide effect at $1 \%$. This finding is in agreement with data referred by Singh et al., 2018, who report a larvicide effect in R. microplus.

Data about the repellency of the components agreed with recent literature. Indeed, citronellol $7 \%$ resulted repellent (Ferreira et al., 2017) as well as geraniol 1\% (Khallaayoune et al., 2009) and 1,8-cineol (Pålsson et al., 2008), while linalool (Tabari et al., 2017) and linalyl-acetate scored uneffective.

Eucalyptus globulus EO showed the lowest MIC (2.5\%) versus $S$. brevicaulis. This mold has been recognized as an endosymbiotic of Amblyomma americanum and Dermacentor variabilis (Yoder et al., 2005) and is proven to protect this latter from pathogenic actions of M. anisopliae (Yoder et al., 2008).

\section{REFERENCES}

Aw, K. M. S., and Hue, S. M. (2017). Mode of infection of Metarhizium spp. fungus and their potential as biological control agents. J. Fungi 3:E30. doi: 10.3390/jof3020030

Banumathi, B., Vaseeharan, B., Rajasekar, P., Prabhu, N. M., Ramasamy, P., Murugan, K., et al. (2017). Exploitation of chemical, herbal and nanoformulated acaricides to control the cattle tick, Rhipicephalus (Boophilus) microplus - A review. Vet. Parasitol. 244, 102-110. doi: 10.1016/j.vetpar.2017.07.021

Bravo, A., Gill, S. S., and Soberon, M. (2007). Mode of action of Bacillus thuringiensis cry and cyt toxins and their potential for insect control. Toxicon 49, 423-435. doi: 10.1016/j.toxicon.2006.11.022

Brown, R. S., Reichelderfer, C. F., and Anderson, W. R. (1970). An endemic disease among laboratory population of Dermacentor andersoni (D. venustus) (acarina:Ixodidae). J. Invertebr. Pathol. 16, 142-143. doi: 10.1016/00222011(70)90220-X
Furthermore, both entomopathogenic fungi examined in the present study resulted resistant to such EO dilution. These data would seem to be of interest if these plant-based acaricides would be applied to control other ticks.

Metarhizium anisopliae showed a limited sensitivity against the selected EOs, while B. bassiana appeared to be sensitive to $1 \%$ of $L$. hybrida. The acaricide concentrations of $L$. hybrida and $P$. graveolens EOs have no effectiveness against $P$. mirabilis, but could be lethal for $B$. thuringiensis.

Whereas $P$. mirabilis is a bacterium naturally widespread in the environment, mainly where domestic and/or wild animals are present, $B$. thuringiensis is frequently used in Integrated Pest Management programs for its well-known insecticidal activity (Lucchi and Benelli, 2018). Even though it is considered active against ticks (Samish et al., 2004), B. thuringiensis is usually employed against insects of public health and agricultural importance (Ruiu, 2015). For this reason, the administration of L. hybrida and P. graveolens EOs as biopesticides should be avoided in environment where $B$. thuringiensis-based biocontrol operations are ongoing.

\section{CONCLUSION}

Results presented here show the feasibility of an integrated approach merging the use of tick repellents and microbial entomopathogens for the eco-friendly management of R. microplus. Notably, Beauveria bassiana and Metarhizium anisopliae can be successfully used in presence of $P$. graveolens EO-based repellents, while L. hybrida could be an interesting repellent alternative when $B$. bassiana is not employed. Conversely, a combined use of $B$. thuringiensis and EOs would not be advisable in the Integrated Vector Management of cattle ticks.

\section{AUTHOR CONTRIBUTIONS}

VE, SN, and FM conceived and designed the experiments. CD, SN, LP, and VE performed the experiments. VE, SN, LP, and FM analyzed the data and wrote the paper.

CLSI (2008). Reference Method for Broth Dilution Antifungal Susceptibility Testing of Filamentous Fungi; Approved 541 Standard, 2nd Edn. Wayne, PA: Clinical and Laboratory Standards Institute.

Cruz, B. C., Buzzulini, C., Lopes, W. D., Maciel, W. G., Bichuette, M. A., Felippelli, G., et al. (2015). Effects of different spray formulations on the reproductive parameters of engorged Rhipicephalus (Boophilus) microplus females detached from experimentally infested cattle. Prev. Vet. Med. 122, 70-75. doi: 10.1016/j.prevetmed.2015.09.010

de Souza Chagas, A. C., de Barros, L. D., Cotinguiba, F., Furlan, M., Giglioti, R., de Sena Oliveira, M. C., et al. (2012). In vitro efficacy of plant extracts and synthesized substances on Rhipicephalus (Boophilus) microplus (Acari: Ixodidae). Parasitol. Res. 110, 295-303. doi: 10.1007/s00436-011-2488-z

Drzewiecka, D. (2016). Significance and roles of proteus spp. bacteria in natural environments. Microb. Ecol. 72, 741-758. doi: 10.1007/s00248-015-0720-6

Ebani, V. V., Nardoni, S., Bertelloni, S., Giovanelli, S., Rocchigiani, G., Pistelli, L., et al. (2016). Antibacterial and antifungal activity of essential oils against some 
pathogenic bacteria and yeasts shed from poultry. Flav. Fragr. J. 31, 302-309. doi: $10.1002 /$ ffj.3318

Fernández-Ruvalcaba, M., Peña-Chora, G., Romo-Martínez, A., HernándezVelázquez, V., de la Parra, A. B., and De La Rosa, D. P. (2010). Evaluation of Bacillus thuringiensis pathogenicity for a strain of the tick, Rhipicephalus microplus, resistant to chemical pesticides. J. Insect. Sci. 10:186. doi: 10.1673/ 031.010.14146

Ferreira, L. L., Oliveira Filho, J. G., Mascarin, G. M., León, A. A. P., and Borges, L. M. F. (2017). In vitro repellency of DEET and $\beta$-citronella against the ticks Rhipicephalus sanguineus sensu lato and Amblyomma sculptum. Vet. Parasitol. 239, 42-45. doi: 10.1016/j.vetpar.2017.04.021

González, J., Valcárcel, F., Pérez-Sánchez, J. L., Tercero-Jaime, J. M., Cutuli, M. T., and Olmeda, A. S. (2016). Control of Hyalomma lusitanicum (Acari: Ixodidae) ticks infesting Oryctolagus cuniculus (Lagomorpha: Leporidae) using the entomopathogenic fungus Beauveria bassiana (Hyocreales: Clavicipitaceae) in field conditions. J. Med. Entomol. 53, 1396-1402. doi: 10.1093/j.me/ tjw088

Jonsson, N. N. (2006). The productivity effects of cattle tick (Boophilus microplus) infestation on cattle, with particular reference to Bos indicus cattle and their crosses. Vet. Parasitol. 137, 1-10. doi: 10.1016/j.vetpar.2016.01.010

Kaaya, G. P., Samish, M., Hedimbi, M., Gindin, G., and Glazer, I. (2011). Control of tick populations by spraying Metarhizium anisopliae conidia on cattle under field conditions. Exp. Appl. Acarol. 55, 273-281. doi: 10.1007/s10493-0119471-3

Khallaayoune, K., Biron, J. M., Chaoui, A., and Duvallet, G. (2009). Efficacy of 1\% geraniol (Fulltec) as a tick repellent. Parasite 16, 223-226. doi: 10.1051/parasite/ 2009163223

Klafke, G., Webster, A., Dall Agnol, B., Pradel, E., Silva, J., de La Canal, L. H., et al. (2017). Multiple resistance to acaricides in field populations of Rhipicephalus microplus from Rio Grande do Sul state, Southern Brazil. Ticks Tick Borne Dis. 8, 73-80. doi: 10.1016/j.ttbdis.2016.09.019

Lević, J., Čabarkapa, I., Todorović, G., Pavkov, S., Sredanović, S., CoghillGalonja, T., et al. (2011). In vitro antibacterial activity of essential oils from plant family Lamiaceae. Rom. Biotech. Lett. 16, 6034-6041.

Lucchi, A., and Benelli, G. (2018). Towards pesticide-free farming? Sharing needs and knowledge promotes integrated pest management. Environ. Sci. Pollut. Res. Int. 25, 13439-13445. doi: 10.1007/s11356-018-1919-0

Pålsson, K., Jaenson, T. G., Baeckström, P., and Borg-Karlson, A. K. (2008). Tick repellent substances in the essential oil of Tanacetum vulgare. J. Med. Entomol. 45, 88-93. doi: $10.1093 /$ jmedent/45.1.88

Pirali-Kheirabadi, K., and Teixeira da Silva, J. A. (2010). Lavandula angustifolia essential oil as a novel and promising natural candidate for tick (Rhipicephalus (Boophilus) annulatus) control. Exp. Parasitol. 126, 184-186. doi: 10.1016/j. exppara.2010.04.012

Pirali-Kheirabadi, K., and Teixeira da Silva, J. A. (2011). In-vitro assessment of the acaricidal properties of Artemisia annua and Zataria multiflora essential oils to control cattle ticks. Iran J. Parasitol. 6, 58-65.

Prakash Mishra, A., Sharifi-Rad, M., Shariati, M. A., Mabkhot, Y. N., Al-Showiman, S. S., Rauf, A., et al. (2018). Bioactive compounds and health benefits of edible Rumex species-A review. Cell. Mol. Biol. 64, 27-34. doi: 10.14715/cmb/2018. 64.8 .5

Rachinsky, A., Guerrero, F. D., and Scoles, G. A. (2008). Proteomic profiling of Rhipicephalus (Boophilus) microplus midgut responses to infection with Babesia bovis. Vet. Parasitol. 152, 294-313. doi: 10.1016/j.vetpar.2007.12.027

Ren, Q., Chen, Z., Luo, J., Liu, G., Guan, G., Liu, Z., et al. (2016). Laboratory evaluation of Beauveria bassiana and Metarhizium anisopliae in the control of Haemaphysalis qinghaiensis in China. Exp. Appl. Acarol. 69, 233-238. doi: 10.1007/s.10493-016-0033-6
Rosado-Aguilar, J. A., Arjona-Cambranes, K., Torres-Acosta, J. F. J., RodríguezVivas, R. I., Bolio-González, M. E., Ortega-Pacheco, et al. (2017). Plant products and secondary metabolites with acaricide activity against ticks. Vet. Parasitol. 238, 66-76. doi: 10.1016/j.vetpar.2017.03.023

Ruiu, L. (2015). Insect pathogenic bacteria in integrated pest management. Insects 6, 352-367. doi: 10.3390/insects6020352

Salehi, B., Mishra, A. P., Shukla, I., Sharifi-Rad, M., Contreras, M. D. M., and Segura-Carretero, A. (2018). Thymol, thyme, and other plant sources: health and potential uses. Phytother. Res. doi: 10.1002/ptr.6109 [Epub ahead of print].

Samish, M., Ginsberg, H., and Glazer, I. (2004). Biological control of ticks. Parasitology 129(Suppl.), S389-S403. doi: 10.1017/S0031182004005219

Sharifi-Rad, M., Nazaruk, J., Polito, L., Bezerra Morais Braga, M. F., Esmeraldo Rocha, J., Melo Coutinho, H. D., et al. (2018a). Matricaria genus as a source of antimicrobial agents: from farm to pharmacy and food applications. Microbiol. Res. 215, 76-88. doi: 10.1016/j.micres.2018.06.010

Sharifi-Rad, M., Salehi, B., Sharifi-Rad, J., Setzer, W. N., and Iriti, M. (2018b). Pulicaria vulgaris Gaertn. essential oil: an alternative or complementary treatment for leishmaniasis. Cell. Mol. Biol. 64, 18-21.

Sharifi-Rad, M., Varoni, E. M., Iriti, M., Martorell, M., Setzer, W. N., and Del Mar Contreras, M. (2018c). Carvacrol and human health: a comprehensive review. Phytother. Res. doi: 10.1002/ptr.6103 [Epub ahead of print].

Singh, N. K., Miller, R. J., Klafke, G. M., Goolsby, J. A., Thomas, D. B., and Perez de Leon, A. A. (2018). In-vitro efficacy of a botanical acaricide and its active ingredients against larvae of susceptible and acaricide-resistant strains of Rhipicephalus (Boophilus) microplus Canestrini (Acari: Ixodidae). Ticks Tick Borne Dis. 9, 201-206. doi: 10.1016/j.ttbdis.2017.09.005

Tabari, M. A., Youssefi, M. R., Maggi, F., and Benelli, G. (2017). Toxic and repellent activity of selected monoterpenoids (thymol, carvacrol and linalool) against the castor bean tick, Ixodes ricinus (Acari: Ixodidae). Vet. Parasitol. 245, 86-91. doi: 10.1016/j.vetpar.2017.08.012

Wanzala, W., Hassanali, A., Mukabana, W. R., and Takken, W. (2014). Repellent activities of essential oils of some plants used traditionally to control the brown ear tick, Rhipicephalus appendiculatus. J. Parasitol. Res. 2014:434506. doi: 10. $1155 / 2014 / 434506$

Wanzala, W., Sika, N. F. K., Gule, S., and Hassanali, A. (2004). Attractive and repellent host odours guide ticks to their respective feeding sites. Chemoecology 14, 229-232. doi: 10.1007/s00049-004-0280-6

Yoder, J. A., Benoit, J. B., Denlinger, D. L., Tank, J. L., and Zettler, L. W. (2008) An endosymbiotic conidial fungus, Scopulariopsis brevicaulis, protects the American dog tick, Dermacentor variabilis, from desiccation imposed by an entomopathogenic fungus. J. Invertebr. Pathol. 97, 119-127. doi: 10.1016/j.jip. 2007.07.011

Yoder, J. A., Benoit, J. B., Rellinger, E. J., and Telford, S. R. III (2005). Failure of ticks to transmit Scopulariopsis brevicaulis (Deuteromycota), a common filamentous fungal commensal of ticks. J. Med. Entomol. 42, 383-387. doi: 10.1093/jmedent/ 42.3 .383

Conflict of Interest Statement: The authors declare that the research was conducted in the absence of any commercial or financial relationships that could be construed as a potential conflict of interest.

Copyright (C) 2018 Nardoni, Ebani, D’Ascenzi, Pistelli and Mancianti. This is an open-access article distributed under the terms of the Creative Commons Attribution License (CC BY). The use, distribution or reproduction in other forums is permitted, provided the original author(s) and the copyright owner(s) are credited and that the original publication in this journal is cited, in accordance with accepted academic practice. No use, distribution or reproduction is permitted which does not comply with these terms. 